\title{
INFORMAÇÃO AMBIENTAL PARA A COMUNIDADE CIENTÍFICA
}

\author{
Antonio Teixeira de Barros
}

\begin{abstract}
Resumo
Analisa o discurso informativo dirigido ao público científico sobre meio ambiente, no período de janeiro de 1990 a junho de 1992, com base nos textos publicados pelo Jornal da Ciência Hoje (atualmente Jornal da Ciência), periódico publicado quinzenalmente pela Sociedade Brasileira para o Progresso da Ciência (SBPC). Elencou-se treze categorias temáticas para a análise de conteúdo, optando portanto, pela análise categorial enquanto método de pesquisa para o corpus selecionado no referido jornal. A agenda de eventos ecológicos no âmbito da comunidade científica aparece em primeiro plano na cobertura do jornal. A Amazônia é o segundo tópico em termos de expressividade, seguida das categorias espécies ameaçadas de extinção, informação ambiental e poluição. A cobertura é abrangente e contextualizada.
\end{abstract}

\section{Palavras-Chave}

Comunidade Científica; Sociedade para o Progresso da Ciência; Ecologia/Meio Ambiente; Comunicação Científica; Jornal da Ciência Hoje/Jornal da Ciência.

\footnotetext{
${ }^{1}$ Este trabalho faz parte de uma pesquisa mais ampla acerca dos discursos do Estado, da Ciência e da Imprensa sobre meio ambiente no Brasil.
} 


\section{INTRODUÇÃO}

O objetivo deste estudo é analisar como o Jornal da Ciência Hoje (atualmente Jornal da Ciência) se reportou à questão ambiental no período de 1990 até meados de 1992, quando se realizou a Rio 92. Especificamente, pretendemos examinar o enfoque adotado e a temática enfatizada.

Partimos do pressuposto de que o discurso informativo, voltado para a comunidade científica e para o público interessado em ciência, não se limita apenas a focalizar os efeitos da degradação ambiental sobre a natureza e a sociedade, nem tampouco a publicar diagnósticos ou denúncias, apontando possíveis e adequadas soluções, mas se propõe a abordar a temática com mais profundidade e de forma menos fragmentada.

Para a consecução do objetivo proposto, analisamos uma amostra de textos do Jornal da Ciência Hoje. A opção pelo exame de uma publicação da SBPC justifica-se pelo fato de que, ao longo de sua trajetória, a Sociedade destacou-se como uma das primeiras entidades da sociedade civil a dedicar-se ao exame da questão ambiental no Brasil. Enquanto a temática só passou a preocupar outras instituições a partir da repercussão da Conferência de Estocolmo, em 1972, a SBPC, muito antes, desde 1965, já se ocupava com a questão, como registra Fernandes (1990) e Ferreira (1993). Outra contribuição importante, apontada por Viola \& Leis (1992) diz res- peito ao debate inter e multidisciplinar protagonizado pela Sociedade no âmbito da comunidade científica nacional, a partir de 1980. Algumas áreas já estavam efetivamente engajadas nos estudos ecológicos, tais como: Geografia, Direito, Engenharia, Medicina Sanitária e Sociologia. A SBPC exerceu importante papel, atuando como catalisador desse movimento, produzindo significativos documentos e críticas ao programa nuclear; modelo de desenvolvimento energético; defesa de uma estratégia viável de conservação da biodiversidade na Amazônia, na Mata Atlântica e no Pantanal, por exemplo.

Não se pode olvidar ainda o projeto dos seminários nacionais "Universidade e Meio Ambiente", promovidos anualmente pela SBPC, a partir de 1986. Sem dúvida, tal iniciativa representou um passo importante para criar um fórum de debate continuado no seio da comunidade científica brasileira sobre os temas atinentes à educação ambiental, à pesquisa científica e a outros assuntos de interesse acadêmico no âmbito da temática ecológico-ambiental.

No caso específico das Ciências Sociais, destaca-se a atuação da Associação Nacional de Pós-Graduação e Pesquisa em Ciências Sociais (ANPOCS), filiada à SBPC, com a instituição do grupo de trabaIho "Ecologia e Sociedade", em 1988. Diversos temas têm sido abordados ao longo desses anos, tais como: o papel do Estado e da sociedade na conjuntura ecossistêmica; os limites políticos e institucionais

Inf.Inf., Londrina, v. 5, n. 1, p. 07-22, jan./jun. 2000 
do ecodesenvolvimento; a evolução da questão ecológica e das políticas ambientais no Brasil; meio ambiente, qualidade de vida e cidadania; a devastação na Amazônia; os processos migratórios; e outros temas atinentes à problemática ambiental e as Ciências Sociais no Brasil (Vieira, 1992).

Quanto à metodologia, optamos pela análise categorial, própria da análise de conteúdo (AC), sendo esta entendida como "um método de tratamento e análise de informações, colhidas por meio de técnicas de coleta de dados, consubstanciadas em um documento" (Chizzotti, 1991, p.98). Autores como Bardin (1977), Stone (1971) e Williams (1985) também defendem a AC como um rico instrumento de pesquisa no campo das Ciências Sociais, porque se aplica à análise de discursos extremamente diversificados, com base na categorização sistemática e objetiva do conteúdo manifesto no texto e na dedução de inferências, ou seja, uma "segunda leitura", centrada nos aspectos latentes da mensagem, vale dizer, o potencial inédito em termos de sentido, o não-dito. Por meio da análise categorial, é possível realizar um inventário dos temas abordados, primeiro passo para analisar o enfoque adotado e identificar as áreas de conhecimento predominantes, de acordo com o que nos propomos. Para tanto, após a catalogação dos 103 textos que compõem a amostra, estabelecemos as seguintes categorias, sendo que nem todas aparecem em todos os periódicos:
1 - Amazônia - todos os estudos que abordam especificamente a região amazônica;

2 - Desertificação - análises do avanço da desertificação no Brasil e no mundo;

3 - Devastação/Desmatamento - exame dos efeitos e conseqüências, fora do contexto amazônico;

4 - Educação Ambiental - relatos de iniciativas educativas no sistema de ensino formal;

5 - Espécies em Extinção - artigos que abordam a situação das espécies animais e vegetais ameaçadas de extinção

6 - Eventos Científicos/Ecológicos - notícias e sínteses de eventos científicos voltados para a questão ambiental;

7 - Financiamento de ecoprojetos - matérias relativas à liberação de recursos para a execução de projetos ecológicos;

8 - Informação Ambiental - aspectos atinentes ao universo da informação e documentação no campo da ecologia;

9 - Legislação/Acordos ambientais - textos que enfocam aspectos jurídicos da questão ecológica;

10 - Pesquisas e tecnologias ambientais informações sobre estudos ambientais; 11 - Política Ambiental - informações relativas à elaboração e implementação de políticas públicas "verdes";

12 - Poluição - temas centrados nas diversas formas de poluição ambiental, sobretudo a industrial;

13 - Rio 92 - opiniões, dados e informações sobre os preparativos para a UNCED; 


\section{Agenda Eco-científica}

Até mesmo devido ao seu caráter acentuadamente informativo, bem como ao contexto particular do período - a realização de encontros e conferências para discutir a participação da comunidade científica na Conferência da ONU - o JCH destacou a informação e a síntese relativas a eventos de natureza científico-ecológica, dedicando exatamente 17 páginas de suas edições do primeiro semestre de 1992. Em todos esses eventos foram discutidos temas de cunho estritamente ambiental, como também assuntos de caráter político, eco- nômico e social, por exemplo: migrações, reforma agrária, violência e urbanização agressiva, tecnologias industriais e de despoluição, ética ambiental e cooperação internacional na área ambiental, planejamento urbano, formas de uso do solo, destruição da camada de ozônio, política energética e de biotecnologias.

\section{Amazônia}

Esta categoria foi a que mereceu mais destaque, depois da agenda de eventos científicos/ecológicos, na cobertura do $\mathrm{JCH}$, com $10,70 \%$ da amostra (Tabela 1). Con-

\section{TABELA 01}

Jornal da Ciência Hoje - classificação temática

$\begin{array}{llllll}\text { C a t e g o r i a s / P e r í o d o } & \mathbf{1 9 9 0} & \mathbf{1 9 9 1} & \mathbf{1 9 9 2} & \text { Total - N } & \text { Total - \% } \\ \text { 1 - Amazônia } & 06 & 04 & 01- & 11 & 10,70 \\ \text { 2 - Desertificação } & 03 & -- & -- & 03 & 2,90 \\ \text { 3 - Devastação } & -- & 03 & -- & 03 & 2,90 \\ \text { 4 - Educação ambiental } & 01 & 01 & -- & 02 & 1,90 \\ \text { 5 - Espécies em extinção } & 08 & -- & -- & 08 & 7,80 \\ \text { 6 - Eventos científicos/ecológicos } & -- & 02 & 34 & 36 & 35,00 \\ \text { 7 - Financiamentos de ecoprojetos } & 02 & -- & 01- & 03 & 2,90 \\ \text { 8 - Informação ambiental } & 02 & 02- & 04 & 08 & 7,80 \\ \text { 9 - Legislação/Acordos ambientais } & 02 & 03 & -- & 05 & 4,85 \\ 10 \text { - Pesquisas/tecnologias ambientais } & 02 & 02 & 01 & 05 & 4,85 \\ 11 \text { - Política ambiental } & 03 & 01 & -- & 04 & 3,80 \\ 12 \text { - Poluição } & 05 & 03 & -- & 08 & 7,80 \\ 13 \text { - Rio 92 } & -- & 05 & 02 & 07 & 6,80 \\ \quad \text { T o t a I } & 34 & 26 & 43 & 103 & 100,00\end{array}$


templou assuntos como zoneamento ecológico-econômico, riquezas naturais, biodiversidade, queimadas, desmatamento, mineração, índios, pobreza, pesquisas ambientais e desenvolvimento auto-sustentável. Aparentemente, a pauta do referido periódico é similar à da imprensa convencional. Contudo, a abordagem é radicalmente distinta. Enquanto a grande imprensa concentra-se em aspectos específicos dos fatos ecológicos, o JCH apresenta um enfoque mais abrangente e contextualizado, ampliando o horizonte de compreensão do leitor. Citamos como exemplo, de modo especial, duas matérias estreitamente relacionadas. A primeira "Forest 90 rejeita exploração irracional" (19.10.96) tem como mote a realização do I Simpósio Internacional de Estudos Ambientais em Florestas Tropicais Úmidas, no qual a Amazônia esteve em foco. O Jornal teria muitas razões para prender-se ao factual. Todavia, o texto foi didaticamente subdividido em várias partes, cujos entretítulos fornecem uma boa visão da amplitude do enfoque adotado: (a) "Queimadas afetam química atmosférica"; (b) "Desmatamento e política florestal"; (c) "Sistema extrativista em discussão"; (d) "Continua a dizimação dos povos indígenas".

A outra matéria, intitulada "Favor não falar em Amazônia sem ouvi-la” (1991) também poderia resumir em algumas linhas 0 que aconteceu, quando e onde, uma vez que também se trata de um evento, o "Seminário Internacional sobre Meio Ambiente, Pobreza e Desenvolvimento na Amazônia". Porém, da mesma forma que o texto anterior, há oito entretítulos que oferecem uma gama de informações relacionadas com a temática em tela:

- "Pesquisa" (acerca da atuação da comunidade científica nacional no que se refere à pesquisa ambiental);

- "Código" (Código Nacional do Meio Ambiente);

- "Primeiros projetos" (projetos relativos à primeira etapa do Plano de Desenvolvimento da Amazônia);

- "Madeira" (extração de);

- "Pobreza" (relação entre problemas ambientais, sociais e econômicos);

- "Monopólios" (na comercialização de produtos extrativistas);

- "Biodiversidade" (desaparecimento drástico de espécies);

- "12 mil anos" (projetos arqueológicos).

Outra constatação decorrente da própria natureza da cobertura do $\mathrm{JCH}$ é que os diversos atores envolvidos na questão ambiental são postos em cena. Raramente o jornal limita-se a citar apenas o Governo, ONG's ou cientistas. Ademais, não supervaloriza os atores científicos, o que poderia ocorrer, visto que se trata de um veículo ligado a uma entidade científica. $O$ que pudemos observar é que o Jornal atribui importância a cada ator envolvido na 
questão, dependendo da natureza da informação veiculada. No caso dessas duas matérias, ambas iniciam citando agentes governamentais, o presidente do Ibama e o secretário de Ciência \& Tecnologia e Meio Ambiente do estado do Pará. Contudo, tal atitude é justificada; no primeiro, por ser o Ibama protagonista da discussão relativa ao Brasil no // Forest e no segundo porque o secretário de C\&T e Meio Ambiente do Pará exercia a função de presidente do seminário. O Jornal se diferencia ainda dos demais veículos da imprensa quando cita instituições e entidades, sejam elas governamentais ou não, evitando a personalização, isto é, o destaque às pessoas que exercem cargos de comando.

\section{Espécies Ameaçadas de Extinção}

A extinção de espécies é abordada de forma ampla e a partir de informações de fontes governamentais como o lbama e as universidades federais, bem como de fontes não-governamentais, destacando-se a Fundação Biodiversitas. Tanto elementos da fauna como da flora estão presentes nos textos, mas destacam-se as espécies animais. A cobertura do JHC abrange diversos ecossistemas como a Mata Atlântica, a Amazônia, os estados da Bahia, Espírito Santo, Minas Gerais, Paraná, Pernambuco, Rio de Janeiro e São Paulo. Em termos específicos, o JCH trata das seguintes espécies:

a) ANIMAIS - ararinha azul, guariba, guariba-barbado, muriqui ou mono-carvoeiro, sauá, macaco-prego-do-peitoamarelo, mico-leão-de-cara-dourada, lobo-guará, suçuarana, jaguatirica, gatodo-mato, gato-maracajá, preguiça-decoleira, peixe-boi-marinho, baleia jubarte, ouriço preto, veado campeiro, tartaruga cabeçuda, tartaruga-de-pente, tartarugaverde, tartaruga-gigante, tartaruga comum, surucucu, jacaré-de-papo-amarelo, zabelê ou jaó, macuco-mutum-do-nordeste, arara-azul-de-lear, pintas-silgodo-nordeste, rabilongo, bico-virão-dacaatinga, araponga-do-nordeste, pintorverdadeiro, ferrugem, onças, porcos do mato e Terenura sicki;

b) VEGETAIS - aroeira, baraúna, angico e orquídea (Catleya eldorado).

Entre as notícias, destaca-se uma que menciona a realização de um estudo da Sociedade Brasileira de Zoologia em parceria com a Fundação Biodiversitas sobre o inventário geral das espécies em extinção no Brasil: "do total de 207 espécies listadas, 124 estão assinaladas no Sudeste, 89 no Nordeste, 69 no Sul, 68 no Norte e 51 no Centro-Oeste. O Rio de Janeiro é o estado líder em espécies ameaçadas (84), seguido por São Paulo (80), Espírito Santo (78), Bahia (77) e Minas Gerais (64)". Além disso, o mencionado estudo concluiu que, em 17 anos, mais de 121 animais que não estavam incluídos no rol de ameaçados passaram a fazer parte da lista. A causa principal desse crescimento acelerado é a contínua destruição dos habitats. "Daí a concen- 
tração de espécies ameaçadas no Sudeste, onde a vegetação nativa - Mata Atlântica - está quase totalmente destruída".

\section{Informação Ambiental}

A organização de bancos de dados ambientais, as redes de informação e pesquisa e a questão imprensa versus meio ambiente são os assuntos principais dessa categoria. Os textos abordam da constituição de bancos de dados em si à elaboração de guias informativos sobre pesquisas, cadastros de ecólogos/cientistas e programas de monitoramento ambiental. Sobre as redes de pesquisa, o $\mathrm{JCH}$ destaca tanto redes nacionais, como a Rede de Informações para a Amazônia, como internacionais, a exemplo da Environline.

A relação entre imprensa e meio ambiente é abordada em um texto que informa o que foi debatido no Encontro Internacional de Imprensa, Meio Ambiente e Desenvolvimento, Promovido pelo Green Press, em Belo Horizonte, 1992. O próprio título da matéria "Imprensa concentrada" aponta o direcionamento da abordagem do Green Press, corroborada pelo JCH. Diz o texto que "são empecilhos ao direito à informação a concentração da propriedade dos meios de comunicação social, e a influência econômica, governamental ou privada sobre as linhas editoriais".

O artigo tece várias considerações utópicas e, até certo ponto, ingênuas acer- ca da comunicação pública, como a de que "todas as pessoas têm o direito de serem oportuna e corretamente informadas sobre questões ambientais, e de expressarem suas opiniões através dos meios de comunicação, sem restrições de qualquer ordem" (grifo nosso). Consideramos tal concepção ingênua e utópica não porque discordamos dela, mas porque é notório, no contexto atual, que a mídia não tem essa preocupação. Faz parte de sua própria natureza idiossincrática a seleção dos fatos, o destaque e a supressão de informações, a fragmentação e a personalização dos processos sociais. Outro equívoco das abordagens do teor expresso pelo Green Press é analisar a comunicação social apenas como "meios", "veículos" de comunicação. Sociologicamente, jamais devemos restringir o enfoque a esse aspecto. Trata-se, na verdade, de instituições muito bem articuladas e estruturadas política e economicamente. Nesse aspecto, concordamos com Raymond Williams, quando este se refere à mídia como um conjunto de poderosas instituições culturais, uma vez que nas sociedades contemporâneas estas adquiriram tanta importância quanto as instituições industriais de produção e distribuição de bens (Williams, 1961; 1985).

\section{Poluição}

A análise do período em estudo revela que a poluição não é um tema central na pauta do $\mathrm{JCH}$, o que se depreende nem tanto pela quantidade, quanto sobretudo 
pela dimensão de seus textos. A abordagem aproxima-se daquilo que lemos na imprensa diária: textos curtos, de caráter noticioso/factual. Além disso, a região Sudeste, com destaque para o estado de São Paulo, é o foco principal de atenção. Há ainda uma supervalorização do enfoque científico, o que pode até ser considerado coerente com o caráter editorial do $\mathrm{JCH}$. Contudo, não se pode enfocar o problema exclusivamente sob o aspecto científico, pois os aspectos políticos e econômicos também exercem grande influência nesta área.

Por outro lado, consideramos positivo no enfoque do $\mathrm{JCH}$ o fato de o conteúdo informativo não se prender apenas às mazelas associadas à poluição (ecologia patológica) e muito menos à ética do denuncismo. Ao contrário, os textos, apesar de não relegarem tais aspectos, enfocam projetos e atividades que contribuem ou poderão contribuir para minimizar os efeitos da poluição, como é o caso de um projeto que estuda o potencial de plantas tropicais na aferição da poluição atmosférica e novos métodos para o estudo da chuva ácida e do efeito estufa, bem como o desenvolvimento de inseticida biológico para reduzir a poluição agrotóxica.

\section{Rio 92}

A Rio 92 foi um dos temas importantes na cobertura do $\mathrm{JCH}$, no segundo semestre de 1991 e primeiro de 1992. Além de informações sobre os preparativos e o debate científico, também foi relevante o elemento opinião, sob a forma de artigos assinados. Daí a razão porque não incluímos este tópico na categoria Eventos $\mathrm{Ci}$ entíficos/Ecológicos, preferindo uma análise específica. A participação da comunidade científica foi o elemento principal da cobertura do $\mathrm{JCH}$. Destaca ainda as críticas da comunidade aos preparativos protagonizados pelo Governo, como no caso da mesa-redonda promovida pela SBPC, na qual foi consensual a opinião de que o relatório do governo brasileiro era "omisso e autoritário", porque "não se posiciona sobre as questões que serão decididas no encontro e fixa prazo demasiado curto para a apresentação de propostas" (Relatório omisso e autoritário, ago./1991).

Ainda no que se refere aos textos de cunho informativo, o JCH destaca também atores políticos específicos como o deputado federal Fábio Feldmann, presidente da Comissão de Meio Ambiente da Câmara dos Deputados e a prefeitura do Rio de Janeiro. No primeiro caso, a notícia "Feldmann prega união com ONG's do I Mundo" apresenta as críticas do parlamentar e sua tese de que "o Brasil deve se alinhar às ONG's ambientalistas do I Mundo, para conseguir resultados favoráveis". No segundo caso, a matéria "Esquentando motores para a Rio 92", enfatiza os preparativos da prefeitura do Rio, que incluía um pacote de eventos, como o Fórum Permanente de Debates sobre Meio Ambiente". 
Quanto aos textos opinativos, dois artigos, que, em termos de espaço redacional, são mais expressivos do que os noticiosos, abordam questões de interesse acadêmico. O primeiro, "As Universidades e a Rio 92" (12/4/91), trata do papel da comunidade acadêmica diante da Conferência, considerando-se os diferentes e controvertidos pontos de vista sobre a Universidade. "Muito oficial para as ONG's e muito ONG para o Governo", a Universidade passou a enfrentar sérias dificuldades perante a sociedade no tocante aos preparativos para a UNCED. Diante disso, "o que sobra para as Universidades na Conferência da ONU? questiona o autor. Conclui que a difícil situação das universidades tem raízes em três elementos principais: a estrutura departamental, a natureza dos programas de pós-graduação e os programas de fomento à pesquisa, os quais têm em comum o fato de ainda não terem incorporado a questão ecológica, por ainda ser emergente, tendo dificuldade de ser devidamente contemplada por uma estrutura institucional planejada para atender outras demandas acadêmicas.

O segundo artigo "Meio ambiente: zonas críticas", focaliza a questão do mapeamento "das nove zonas críticas do mundo", pelo Grupo de Estudos de Zonas Críticas de Alterações do Meio Ambiente em Nível Global, da International Geographical Union. Entre as zonas citadas está a Amazônia, que figura em terceiro lugar, "devido aos desmatamentos, queimadas, mineração, falta de demarcação de florestas, de terras indígenas e de parques nacionais, garimpo, assentamento de lotes rurais e falta de estrutura urbana nas cidades" (As demais zonas críticas são: 1- Sul da Flórida; 2- Cidade do México; [(3- Amazônia)]; 4- Mar do Norte; 5 - Montanhas semi-áridas do Quênia; 6 - Mar do Aral; 7 Platô dos Ordos - China; 8 - Floresta Tropical nos Países do Pacífico Sul; 9 - Himalaia).

\section{Legislação Ambiental}

Esta categoria engloba assuntos como: o substitutivo do projeto de política agrícola, em tramitação no Congresso Nacional em 1990, e suas implicações legais na atuação do Ibama e do Conselho Nacional de Meio Ambiente; a necessidade de o Brasil criar leis para regulamentar a importação de espécies exóticas, os dispositivos legais referentes à demarcação de áreas indígenas e o Acordo de Madri, sobre a exploração da Antártica.

A matéria “ 'Mutilação e desfigurações' no Ibama" apresenta o resultado da análise da Comissão de Meio Ambiente da SBPC acerca do substitutivo do projeto de política agrícola em tramitação no Congresso Nacional na época. A Comissão "definiu as alterações propostas para o Ibama como 'grave' retrocesso na política ambiental brasileira". Para a SBPC, o Ibama deve ser prestigiado e mantido em sua integridade. A necessidade de leis para a importação de animais exóticos foi discutida conjuntamente pela UFRGS e pela SBPC, median- 
te a instalação de um criatório de espécies exóticas na cidade de Osório, no estado do Rio Grande do Sul, "sem nenhuma experiência com vida silvestre; e nenhum órgão público (...) foi ouvido, antes da importação e do desembarque dos crocodilos". A questão indígena veio à tona por causa da polêmica gerada pelos decretos que, em 1991, previam revisão da demarcação de terras indígenas. Como decorrência, a Fundação Nacional do Índio (FUNAI) foi fortalecida, mas não agradou a comunidade científica o dispositivo legal permitindo à FUNAI nomear qualquer funcionário administrativo para atuar como se fosse antropólogo. Quanto ao Acordo de Madrid que proíbe a mineração, por mais de 50 anos, na Antártica, o JCH louva a decisão dos 39 países que o assinaram, justificando que "o continente branco é reserva natural dedicada à paz e à ciência".

\section{Pesquisas e Tecnologias Ambientais}

A Biologia é o carro-chefe desse tópico. Os ramos mais citados são: Botânica, Fisiologia Vegetal e Ecologia. O que mais interessa à Botânica são os ecossistemas amazônicos, mas não há preocupação com interesses imediatos. O que importa é conhecer cada vez mais a situação das florestas. Quanto à Fisiologia Vegetal, ao contrário, há interesse claro na aplicação dos estudos à realidade sócioambiental, como é o caso do desenvolvimento de biorreguladores naturais. Os fisiólogos estão engaja- dos na concepção das biotecnolo-gias, cujo fim é a aplicação do conhecimento a uma dada realidade.

Quanto ao caso do outro ramo da Biologia, a Ecologia, temos os resultados de um estudo que utiliza formigas em pesquisas ecológicas com a finalidade de utilizálas como controladoras de pragas. A partir da observação de que $30 \%$ das árvores da Chapada dos Guimarães (MT) "produzem e expelem gotas de néctar para atrair formigas, que, em troca, protegem-nas de insetos herbívoros", o ecólogo concluiu que das muitas espécies de formigas existentes no Brasil, mais de mil podem ser utilizadas na agricultura como controladoras biológicas. Assim como no caso da Fisiologia Vegetal, percebe-se o interesse dos ecólogos pela aplicação de seus estudos a uma realidade específica, no caso, a agricultura.

A Química aparece em segundo lugar, nas pesquisas sobre geração de tecnologia para medição de poluentes na atmosfera, nos grandes centros urbanos. A diferença fundamental entre químicos e biólogos é que para estes a ciência parece estar acima de tudo, sem vínculos políticos, enquanto para aqueles, a tecnologia desenvolvida no Brasil esbarra em um obstáculo quase intransponível do ponto de vista científico: a falta de compromisso governamental para com a ciência. Afinal, "já temos tecnologia para controlar poluição, mas falta vontade política para implementá-la”, declara um dos pesquisadores.

Inf.Inf., Londrina, v. 5, n. 1, p. 07-22, jan./jun. 2000 


\section{Política Ambiental}

A política ambiental proposta pela Escola Superior de Guerra (ESG) constitui o cerne da cobertura do $\mathrm{JCH}$. Dos quatro textos que tratam do assunto, dois referemse à atuação da ESG como formuladora de uma política ambiental. Um deles restringe-se a noticiar a realização do seminário "A Questão do Meio Ambiente no Brasil", o qual se propôs a discutir o papel das pesquisas científicas e tecnológicas como indicadores para a política de meio ambiente, e o dilema desenvolvimento versus conservação. Já o outro texto confronta as posições da ESG com a opinião da SBPC. Para a ESG, ambientalistas, indigenistas e traficantes "São todos inimigos" do mesmo nível, e admite o recurso da guerra contra "os que possam dificultar ou impedir a conquista dos "objetivos permanentes na Amazônia". Em resposta a essa posição da ESG, manifesta no documento "A Estrutura do Poder Nacional para o Ano 2000", a SBPC rejeitou publicamente a 'militarização da política ambiental', no VIII Encontro das Entidades Ambientalistas na SBPC'90. Declarou ainda seu apoio aos movimentos indigenistas e ambientalistas, por acreditar que "o trabalho deles (...) expressa a vontade do povo lavrada na Constituição".

O Ibama e o Ministério de Minas e Energia também são mencionados. O primeiro, no que se refere ao projeto de política agrícola do Governo Federal e o segundo no que toca à relação entre energia $\mathrm{e}$ meio ambiente. Em todos os casos, o JCH destaca as gestões realizadas pela SBPC, seja para criticar publicamente a política governamental, seja para reivindicar a agilização de ações que favoreçam a causa ambiental.

\section{Desertificação}

O avanço da desertificação no mundo e no Brasil. Esta é a preocupação refletida na cobertura do $\mathrm{JCH}$. Em termos gerais, o jornal associa a crescente formação de desertos às mudanças climáticas. A matéria "O mapa da agonia" conclui que "o deserto avança, tomando o lugar da vida" e retrata a situação do Mar de Aral, cuja tendência é desaparecer. Entre 1961 e 1989 o deserto tomou o lugar de cerca de $20 \%$ da área. Os programas de irrigação forçada e o uso indiscriminado da água do rio AmouDarya são citados como os fatores principais do desencadeamento das conseqüências apontadas, uma vez que tudo isso acelerou as transformações radicais nos ecossistemas regionais. Outra notícia refere-se a uma pesquisa que estava em andamento em 1990, nos Estados Unidos, com o objetivo de reproduzir no espaço as condições de vida do deserto do Arizona. Outra notícia também apresenta o contexto global da desertificação, mas concentra-se na situação brasileira, em particular a aceleração do processo nos pampas gaúchos, onde "o solo, muito frágil foi manipulado de modo errôneo, com excesso de gado e tratores". 


\section{Devastação/Desmatamento}

A temática devastação/desmatamento não é central na cobertura do $\mathrm{JCH}$. No período em estudo, o jornal publicou apenas três matérias sobre o assunto, todas em 1991. Uma trata da devastação na Serra do Mar, no estado do Rio de Janeiro, fazendo um balanço da situação nas últimas décadas, quando o desmatamento chegou a 13 mil hectares por ano, o correspondente a $15,95 \%$ do estado. A segunda matéria: Desmatamento no Brasil diminuiu? apresenta um comentário da revista Science, acerca do desmatamento no Brasil, atribuindo a redução desse processo à "eliminação do subsídio aos criadores de gado que costumam substituir as florestas por pastagens". O último texto enfoca a devastação e a depredação no sítio arqueológico da Fundação Museu do Homem Americano, no Parque Nacional da Serra da Capivara, município de São Raimundo Nonato-PI. Conforme a direção do Museu, "os responsáveis são os donos de terras da região, que extraem mármore para fabricar cal (...) A direção do Museu denuncia ainda que a exploração de calcário "pode causar danos incalculáveis ao local”.

\section{Financiamento de Ecoprojetos}

Sob esta rubrica estão assuntos como as exigências do Banco Mundial (Bird) para financiamento de projetos ambientais, a proposta de "pagamento de dívidas com meio ambiente" e a liberação de recursos para pesquisas ecológicas. Apesar de as regras serem válidas para todos os países, o $\mathrm{JCH}$ ressalta o caso específico de um empréstimo ao Ibama, o qual "está em jogo" porque foi solicitado sem considerar o elenco de exigências do Bird: avaliação minuciosa dos impactos ambientais - em se tratando de projetos florestais e construção de hidrelétricas -, bem como consulta à população local. Quanto à proposta de "pagamento de dívidas com meio ambiente", o $\mathrm{JCH}$ refere-se a um consórcio que defende a conversão da dívida externa brasileira em projetos de proteção ao meio ambiente. Finalmente, uma nota informa a liberação de recursos da ordem de 2,5 bilhões para financiar pesquisas ambientais, pela Financiadora de Estudos e Projetos (Finep).

\section{Educação Ambiental}

Esta categoria registrou apenas dois textos durante o período estudado. Uma nota sobre um projeto educativo do Museu do Instituto Butantã, na cidade de São Paulo, que consiste na publicação de folhetos ilustrados, em português e inglês, dirigidos a crianças, que compõem $75 \%$ do público do Museu, com o objetivo de promover a educação ambiental infantil. A outra matéria relata os resultados bem-sucedidos de um projeto comunitário de educação ambiental, executado por pesquisadores do Museu Paraense Emílio Goeldi. Devido ao entusiasmo da população, os pesquisadores decidiram prolongar as atividades por

\footnotetext{
Inf.Inf., Londrina, v. 5, n. 1, p. 07-22, jan./jun. 2000
} 
mais cinco anos. O objetivo é difundir técnicas não-predatórias de pesca e extração de produtos nativos, bem como contar com a população para fiscalizar em conjunto com os guardas florestais a exploração de produtos naturais na região a fim de evitar a degradação ambiental.

\section{COMENTÁRIOS FINAIS}

Nossas observações finais limitar-seão a alguns aspectos da cobertura do periódico analisado e à tentativa de relacionar o estudo proposto com determinados enfoques teóricos, a partir do pensamento de alguns autores vinculados à área de Sociologia da Ciência e Sociologia da Comunidade Científica. Antes, salientamos que os pressupostos enunciados na introdução são confirmados parcialmente. O discurso informativo da SBPC, dirigido à comunidade científica sobre meio ambiente é amplo, mas ainda está muito preso ao campo das Ciências Naturais. Por outro lado, de fato, não há preocupação apenas com diagnósticos e denúncias, o que se verifica especialmente com a análise das pesquisas sobre poluição; além de se tratar de artigos com expressivo grau de profundidade.

Acerca do item mais importante da cobertura do $\mathrm{JCH}$, a agenda ecocientífica, caberia, talvez, questionar a ausência do Nordeste e a pouca expressividade do Norte na agenda de divulgação do periódico da SBPC. É óbvio que a realização de eventos científicos voltados para a ecologia tem sido precária em ambas as regiões. Contudo, ao longo de 21 anos, será que não houve um que fosse digno de divulgação pela SBPC? Será que apenas os eventos do Centro-sul interessam à comunidade científica brasileira?

Ressaltamos ainda algumas considerações sobre a Amazônia, por ser o temachave (depois da agenda de eventos ecológicos). Apesar de já ter sido caracterizado como o Jornal da Ciência enfocou o assunto, gostaríamos de chamar atenção para o interesse de cientistas estrangeiros e de pesquisadores brasileiros vinculados a instituições internacionais de pesquisa, sobretudo universidades norte-americanas. Sabemos que a Amazônia sempre despertou o interesse da comunidade científica internacional, porém, nos últimos anos, certamente não podemos desconsiderar os fatores relativos à globalização. Afinal, o ecologismo é, por excelência, um debate global e uma temática globalizante, como ressaltam Boff (1993) e Leis (1996). Podese inferir ainda que os aspectos sanitários, florestais e botânicos são os predominantes no discurso do $\mathrm{JCH}$ sobre o assunto em apreço. Trata-se, pois, de um discurso que ainda gira em torno da Ecologia como ramo da Biologia, com pouco enfoque para a dimensão social.

Um dado curioso é a inexpressividade do tópico política ambiental. Quais seriam as razões para o silêncio da comunidade científica em relação a esse tema? Afinal, a SBPC tem atuado como porta-voz dessa 
comunidade no que se refere às políticas governamentais para a área de C\&T em vários momentos, como documenta Fernandes (1990). Ao contrário de Amazônia, a categoria política ambiental aparece com pouca expressividade. O quase "silêncio" é muito sintomático, pois o referido jornal constitui não um mero veículo de divulgação científica, mas um instrumento de informação para especialistas, ou seja, para produtores de conhecimento científico. Portanto, é um periódico voltado para o campo científico (Bourdieu, 1983), além de contribuir para a função de legitimação social da produção simbólica (Bourdieu, 1987).

Outra observação a fazer diz respeito à pouca expressividade da categoria educação ambiental. Caberia, questionar, pois, as razões dessa lacuna. Afinal, a educação ambiental é consensualmente apontada como um dos principais instrumentos para aumentar a consciência ecológica e, conseqüentemente, contribuir para mudar padrões de comportamento e de conduta. Por que, então, o Jornal da Ciência Hoje atribui tão pouca importância a esse assunto? Não haveria interesse da comunidade científica e do público interessado em ciência?

Quanto ao enfoque adotado pelo periódico, é patente o predomínio da informação sobre as pesquisas exploratórias na área de ciências naturais, destacando-se: Biologia, Ecologia, Agronomia e Química, o que, por um lado aparenta ser coerente com a noção tradicional desse tipo de es-
Nesse sentido, a perspectiva de

tudos, mas, por outro lado, indica que a comunidade científica brasileira, no sentido abrangente do termo, ainda não está de fato voltada para a questão ecológica. Isso, a nosso ver, constitui indício da incipiência de um campo científico na área de meio ambiente, no Brasil, por ser o periódico que opera com base nos vetores PRODUTOR $<==>$ PRODUTOR de conhecimento.

$\mathrm{Na}$ área das Ciências Sociais, ao longo dos 30 meses de estudo, o jornal em questão publicou apenas alguns comentários que, ao que tudo indica, foram escritos por cientistas sociais (as áreas de conhecimento dos autores foram omitidas). Estes, contudo, não parecem ser interlocutores dos demais pesquisadores. Aliás, os textos a que nos referimos, na realidade, estão à margem das Ciências Naturais. Diante disso, cabe questionar o papel das Ciências Sociais na SBPC, em termos gerais e no que toca especificamente à problemática ambiental. Quais seriam as razões para o aparente silêncio dos sociólogos, cientistas políticos, economistas e geógrafos, por exemplo? Por que o discurso informativo dirigido aos cientistas sociais se resume aos textos dos antropólogos sobre indigenismo e meio ambiente? Será que as publicações da SBPC não estão sendo utilizadas para divulgar a produção desses cientistas? Certamente, são questões que não podem ser respondidas de pronto, mas, sem dúvida, indicam a necessidade de investigação mais detalhada.

Inf.Inf., Londrina, v. 5, n. 1, p. 07-22, jan./jun. 2000 
Foucault sobre a relação entre saber e poder poderia ser bastante elucidativa (Foucault, 1985; Machado, 1981). Para ele, ciência e saber são diferentes, o que pode ser uma explicação para a ênfase que as publicações da SBPC conferem às Ciências Naturais, consideradas 'mais científicas', enquanto as Ciências Sociais poderiam ser associadas a outros saberes, desprovidos do rigor científico stricto sensu. Além disso, argumenta Foucault, a produção de ciência ou de saber depende não só das condições institucionais, mas também do próprio poder gerado pelo saber. Assim, a primazia do discurso das Ciências Biológicas sobre meio ambiente, talvez pudesse ser explicada com base no poder gerado pelo próprio conhecimento desenvolvido por esse ramo científico ou, pelo menos, poderia ser um ponto de partida para um novo enfoque sobre o assunto.

\section{REFERÊNCIAS BIBLIOGRÁFICAS}

BARDIN, Laurence. Análise de conteúdo. Lisboa : Edições 70, 1977.

BOFF, Leonardo. Ecologia, mundialização e espiritualidade. São Paulo : Ática, 1993.

BOURDIEU, Pierre. O Campo científico. In: ORTIZ, Renato (Org.). Pierre Bourdieu: Sociologia. São Paulo : Ática, 1983, p.122-155.

. O mercado dos bens simbólicos. In: . Economia das trocas simbólicas. São Paulo : Perspectiva, 1987. p.99-182.

CHIZZOTTI, Antonio. Pesquisa em Ciênci- as Humanas e Sociais. Rio de Janeiro : Cortez, 1991.

FERNANDES, Ana Maria. A construção da ciência no Brasil e a SBPC. Brasília : EdUnB, 1990.

FERREIRA, Lúcia Costa. Os fantasmas do vale: qualidade ambiental e cidadania. Campinas : EdUnicamp, 1993.

FOUCAULT, Michel. História da sexualidade: a vontade de saber. Rio de Janeiro : Graal, 1985. v. I.

LEIS, Héctor R. O Labirinto: ensaios sobre ambientalismo e globalização. São Paulo : Gaia, 1996.

MACHADO, Roberto. Ciência e saber. a trajetória de Foucault. Rio de Janeiro : Graal, 1981.

STONE, Philip J. A análise de conteúdo da mensagem. In: COHN, Gabriel (Org.). Comunicação e Indústria Cultural. São Paulo : Nacional, 1971.

VIEIRA, Paulo Freire. A problemática ambiental e as ciências sociais no Brasil. Boletim Informativo e Bibliográfico de Ciências Sociais, n.33, p.3-32, 1992.

VIOLA, Eduardo J., LEIS, Hector R. A evolução das políticas ambientais no Brasil, 1971-1991: do bissetorialismo preservacionista ao multissetorialismo orientado para o desenvolvimento sustentável. In: HOGAN, D. J., VIEIRA, P. F. (Orgs.). Dilemas socioambientais e desenvolvimento sustentável. Campinas : Ed. Unicamp, 1992. p.73-102.

WILLIAMS, Raymond. Culture and society. London : Penguin, 1985. The growth of the reading public. In: $\quad$ The long revolution. London : Chatto \& Windus, 1961. p.156172.

. In: The growth of the popular press. London : Chatto \& Windus, 1961 p.173 213. 


\section{Antonio Teixeira de Barros}

Mestre em Comunicação Social, na área de Comunicação e Processos Sociais, pela Universidade de Brasília (UnB) e doutorando em Sociologia na mesma Universidade, na área de Ciência \& Tecnologia e Sociedade

Professor do Curso de Comunicação Social do Centro Universitário de Brasília-CEUB

\section{Title}

Environmental Information to the Scientific Community

\section{Abstract}

The present work analyses the informative discourse about the environment addressed to the scientific community from January 1990 to June 1992, based on texts published by Jornal da Ciência Hoje (The Journal of Science Today) (presently called Jornal da Ciência), a journal published every fortnight by Sociedade Brasileira para o Progresso da Ciência - SBPC (The Brazilian Society for The Progress of Science). Thirteen thematic categories were listed, according to content, and a category analysis was used as the research method for the corpus selected in the journal. The agenda for the ecological events for the scientific community is shown in first plan in the journal cover. The Amazon region is the second topic in terms of projection, followed by the categories of endangered species, environmental information and pollution. The coverage is broad and contextualized.

\section{Keywords}

Scientific Community. "Sociedade Brasileira para o Progresso da Ciência". Ecology / Environment. Scientific Communication. "Jornal da Ciência Hoje" / "Jornal da Ciência".

\section{Titulo}

Información ambiental para la comunidad científica

\section{Resumen}

Analiza el discurso informativo direccionado al público científico sobre medio ambiente, en el período de enero de 1990 a junio de 1992, con base en los textos publicados por "Jornal da Ciência Hoje" (actualmente "Jornal da Ciência”), periódico publicado a cada quince días por la Sociedade Brasileira para o Progresso da $\mathrm{Ci}$ ência (SBPC). Fueron seleccionadas trece categorías temáticas para el análisis de contenido, optándose por el análisis categorial como método de pesquisa para el corpus seleccionado en el ya mencionado periódico. La agenda de eventos ecológicos en el ámbito de la comunidad científica aparece en destaque en la cobertura del periódico. Amazonia es el segundo tópico en términos de expresividad, seguida de las categorías especies amenazadas de extinción, información ambiental y contaminación. La cobertura periodística es amplia y contextualizada.

\section{Palabras-Clave}

Comunidad Científica; Sociedade Brasileira para o Progresso da Ciência; Ecología/Medio Ambiente; Comunicación Científica; Jornal da Ciência Hoje; Jornal da Ciência.

Artigo recebido em: 08/04/99 